FERNANDO AUGUSTO BENTES DE SOUZA COSTA

REPRESENTAÇÕES DE SI DE PROFESSORES DO ENSINO FUNDAMENTAL:

UM ESTUDO SOBRE A VIRTUDE DO AMOR

SÃO PAULO

2007 


\section{REPRESENTAÇÕES DE SI DE PROFESSORES DO ENSINO FUNDAMENTAL: \\ UM ESTUDO SOBRE A VIRTUDE DO AMOR}

Tese apresentada ao Instituto de Psicologia da Universidade de São Paulo como requisito parcial para a obtenção do título de Doutor em Psicologia

Área de concentração: Psicologia Escolar e do Desenvolvimento Humano

Orientadora: Prof ${ }^{\mathrm{a}}$. Dr ${ }^{\mathrm{a}}$. Maria Thereza Costa Coelho de Souza

São Paulo

2007 
AUTORIZO A REPRODUÇÃO E DIVULGAÇÃO TOTAL OU PARCIAL DESTE TRABALHO, POR QUALQUER MEIO CONVENCIONAL OU ELETRÔNICO, PARA FINS DE ESTUDO E PESQUISA, DESDE QUE CITADA A FONTE.

Catalogação na publicação

Serviço de Biblioteca e Documentação

Instituto de Psicologia da Universidade de São Paulo

Souza Costa, Fernando Augusto Bentes de.

Representações de si de professores do ensino fundamental: um estudo sobre a virtude do amor / Fernando Augusto Bentes de Souza Costa ; orientadora Maria Thereza Costa Coelho de Souza. --São Paulo, 2007.

$136 \mathrm{p}$.

Tese (Doutorado - Programa de Pós-Graduação em Psicologia. Área de Concentração: Psicologia Escolar e do Desenvolvimento Humano) - Instituto de Psicologia da Universidade de São Paulo.

1. Virtudes 2. Amor 3. Representações de si 4. Professores 5. Ensino fundamental 6. Valores I. Título.

BJ1518 


\section{REPRESENTAÇÕES DE SI DE PROFESSORES DO ENSINO FUNDAMENTAL: UM ESTUDO SOBRE A VIRTUDE DO AMOR}

Fernando Augusto Bentes de Souza Costa

\section{BANCA EXAMINADORA}

(Nome e assinatura)

(Nome e assinatura)

(Nome e assinatura)

(Nome e assinatura)

(Nome e assinatura)

TESE DEFENDIDA E APROVADA EM

iii 
A minha mãe Bernardette (in memorian) e à professora Graciete (minha professora de alfabetização) primeiros exemplos de pessoas amorosas que a vida me presenteou

A todos os Mestres e Mestras desse nosso imenso Brasil que continuam sonhando, acreditando e realizando cotidianamente uma Educação de Qualidade 


\section{AGRADECIMENTOS}

Ao Ricardo Ampudia, amigo e companheiro, exemplo do Amor Philia que tanto me apoiou e incentivou ao longo dessa jornada que ora chega ao seu ponto parágrafo. Agradeço por sua generosidade e paciência, virtudes essenciais no existir humano;

Aos meus familiares que mesmo à distância torceram por essa conquista;

À professora e doutora Maria Thereza Costa Coelho de Souza, que pacientemente orientou esse trabalho com cuidado e atenção;

Ao Dr. Daniel Delouya que, junto comigo, me fez pensar e acreditar que a Vida é, na verdade, a grande Tese da existência humana e que, portanto, deve ser defendida e vivida o mais amorosamente possível;

À amiga psicanalista e professora Iaraci Advíncula por ter me mostrado com a sua Tese a beleza que é o imponderável humano;

Aos professores e professoras que aceitaram participar dessa pesquisa; a eles e elas que com razão e afeto me mostraram um pouco de suas vidas dedicadas ao ofício de Ensinar, espero ter conseguido mostrar um pouco de tudo o que vi e ouvi;

Às colegas e companheiras de estudo Luciene Tognetta, Luciana Caetano, Patrícia Sampaio e Ana Flávia Castanho por sua ajuda atenciosa e gentil;

Aos profissionais da educação que me auxiliaram de alguma forma a ter acesso aos professores e professoras participantes de nossa pesquisa: coordenadores de série, diretoras de escola, supervisoras escolares. A todos e todas, agradeço sinceramente;

À professora doutora Rosely Brenelly e ao professor doutor Yves de La Taille por terem aceito participar de minha banca de qualificação e pelas contribuições valiosas para a conclusão do trabalho;

Às professoras e doutoras Fátima Lukjanenko e Jussara Tortella por terem aceito participar da banca examinadora;

À amiga e professora doutora Helena Dias por sua torcida vibrante e permanente. Aos amigos Fábio e Bia por sua amizade reconfortante e por sua torcida entusiasmada;

À amiga Nazaré Palheta ainda que distante por sua vibração calorosa e acolhedora; 
Às amigas Denise Frade e Suzana Pastori pela amizade generosa e acolhedora;

Ao Dr. Ricardo Soares pelo cuidado e apoio num momento tão delicado dessa trajetória;

Ao Instituto de Psicologia em seus órgãos colegiados (CPP e CPG) e à PróReitoria de Pesquisa e Pós-Graduação da USP por terem acolhido minha necessidade de um tempo maior para a conclusão desse trabalho;

À Universidade do Estado do Pará, à CAPES pelo apoio financeiro e institucional. 
“Quando os homens são amigos, não é mais necessária a justiça entre eles; se foram justos, eles terão ainda necessidade da amizade”

Aristóteles - Ética a Nicômaco 


\section{SUMÁRIO}

Resumo

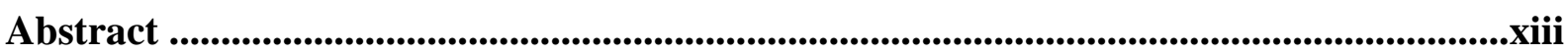

Introdução

Capítulo I - Da moral e das virtudes a perspectiva da Filosofia ................................... 3

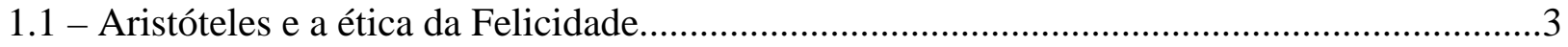

1.2 - Kant e a moral do Dever: os imperativos categóricos e hipotéticos .....................................7

1.3 - Comte-Sponville e o absoluto relativo: entre a moral e a ética ....................................... 11

1.4 - Charles Taylor e a orientação para o Bem ...................................................................13

Capítulo II - O Si Mesmo, as Representações de Si ....................................................................17

2.1 - A Contribuição da Psicologia Genética de Jean Piaget .....................................................17

2.2 - As representações de si: a contribuição: a contribuição de Perron .....................................19

Capítulo III - Inteligência, Afetividade e moral: relações de constituição genética e

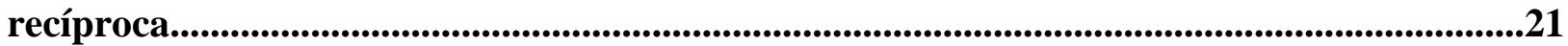

3.1 - Alguns apontamentos sobre aspectos metodológicos da pesquisa .................................27

Capítulo IV - As virtudes morais: da sua importância e do seu estatuto científico ............. 32

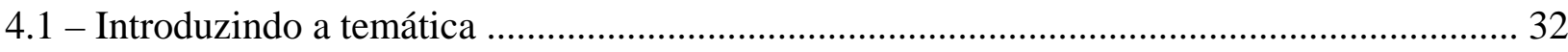

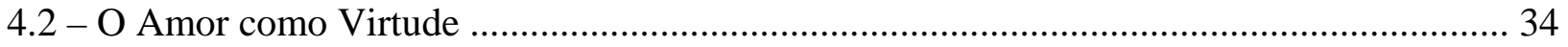

Capítulo V - As pesquisas psicológicas sobre Virtudes ............................................................ 39

Capítulo VI - Da educação, do trabalho docente e da figura do mestre-professor................56

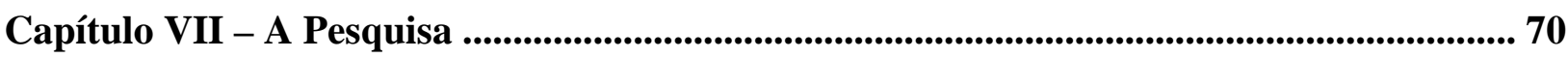

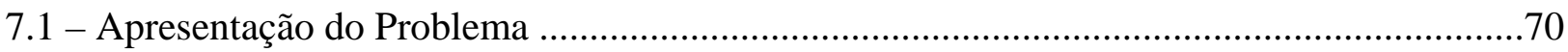

Problema, Hipótese, Objetivo Geral, Objetivos Específicos, Método, Participantes ...................71

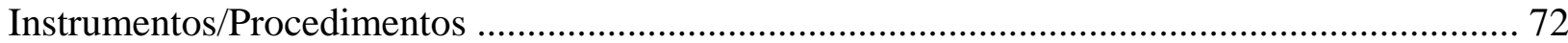

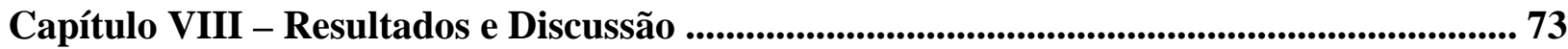

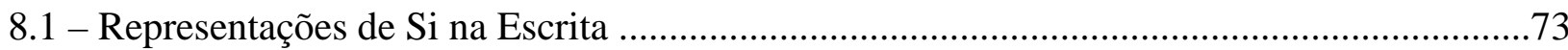

8.2 - Representações de Si nas Entrevistas ....................................................................... 84

Capítulo IX - Considerações Finais ............................................................................. 117 
Anexo I - Pedido de autorização para a coleta de dados.............................................. 119

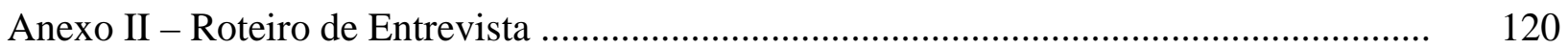

Anexo III - Orientações para o texto escrito (Memorial).................................................. 121

Anexo IV - Exemplos de três Memoriais seguidos das respectivas Entrevistas ................. 122

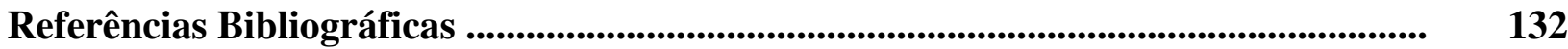




\section{LISTA DE QUADROS}

Quadro 1. Categorias encontradas para a pergunta Quem sou eu como professor? 74

Quadro 2. Categorias encontradas para a questão "Fale três palavras que te descrevem ou te definem como professor(a)

Quadro 3. Categorias construídas para a questão: "Das três palavras, destaque uma” .87

Quadro 4. Categorias encontradas para a questão "Fale um sentimento que te define como Professor (a)" .91

Quadro 5. Categorias encontradas para a questão: "Que valores você defende como Professor?”

Quadro 6. Categorias encontradas para a questão: "Destaque um dos valores que você Citou.....

Quadro 7. Categorias construídas para a questão: “Cite uma pessoa que você admira. Pode ser um ser humano, do contexto geral ou um educador”....

Quadro 8. Categorias encontradas para a questão: “O que você admira nessa pessoa?”...105

Quadro 9. Categorias construídas para a resposta à questão: "O que te faz continuar sendo Professor(a)?” 


\section{LISTA DE TABELAS}

Tabela 1. Distribuição das Categorias construídas sobre as Representações de Si constatadas nos Memoriais escritos

Tabela 2. Distribuição das respostas (três palavras Enunciadas) pelos sujeitos que o definem e caracterizam como professor/a. 86

Tabela 3. Distribuição das respostas dis sujeitos com relação à palavra destacada .87

Tabela 4. Distribuição das respostas enunciadas pelos sujeitos com relação ao sentimento Escolhido

Tabela 5. Distribuição das respostas sobre os Valores defendidos pelos sujeitos enquanto Professores

Tabela 6. Distribuição das respostas sobre o Valor destacado pelos sujeitos 96

Tabela 7. Distribuição das respostas dos sujeitos para a questão: "Cite uma pessoa que você Admira: um ser humano, do contexto geral, um educador, uma educadora, etc. 103

Tabela 8. Distribuição das respostas dos sujeitos sobre o que admiram nas pessoas escolhidas 105

Tabela 9. Distribuição das respostas dos sujeitos sobre os motivos que os levam a permanecer no Magistério. 


\section{RESUMO}

Souza Costa, F. A. B. de S. Representações de Si de Professores do Ensino Fundamental: um estudo sobre a Virtude do Amor. São Paulo, 2007, 136 p. Tese (Doutorado). Instituto de Psicologia. Universidade de São Paulo.

Discutir os vínculos dos professores com o Magistério e explicar como esses vínculos se mantêm e se conservam é também uma das tarefas que a Psicologia Moral precisaria incorporar em seu campo de investigação, considerando-se a urgência de se refletir sobre a dimensão moral presente na subjetividade dos professores, e acreditando que as virtudes humanas são disposições que compreendem uma multiplicidade de aspectos: afetivos, cognitivos, sociais, culturais, históricos e outros. Além disso, no cenário sócio-educacional brasileiro contemporâneo consideramos da maior relevância saber o que pensam os professores, que vínculos estabelecem com a sua profissão, suas aspirações, motivações, princípios e valores. Essas inquietações conduziram-nos a investigar que representações fazem de si professores do Ensino Fundamental. Representações de Si são imagens que o sujeito faz de si mesmo e construídas como um conjunto de valores. Para isso, realizamos uma investigação com 60 professore(a)s do Ensino Fundamental de $5^{\mathrm{a}}$ à $8^{\mathrm{a}}$ série de diferentes cidades brasileiras situados na faixa etária entre $21 \mathrm{a}$ 60 anos. Indagamo-nos também se e como a virtude do Amor comparecia nessas representações de si. A investigação buscou identificar as figuras admiradas pelos sujeitos bem como as características admiráveis em tais pessoas. Os resultados a que nossa investigação chegou apontaram que: os participantes se representam como professores apaixonados; relataram atitudes positivas frente à Educação, ao ensinar, ao aluno e seu aprendizado e se mostraram curiosos e interessados no conhecimento. As informações colhidas revelaram também as seguintes questões: a formação humana dos alunos e alunas, seu desenvolvimento e aprendizagem apareceram como uma meta educativa; o amor, a paixão, a alegria se destacaram como fundamentais para o ensinar. Valores Morais como: Respeito, Responsabilidade, Solidariedade, Companheirismo foram igualmente apontados pelos professores como importantes para serem incentivados nos alunos. Por fim, constamos a pertinência de nossa hipótese segundo a qual os professores que apresentam a Virtude do Amor como uma dimensão destacada em suas Representações de Si sentem-se satisfeitos e realizados pessoal e profissionalmente.

Palavras-chaves: Virtudes-Amor-Representações de Si- Professores - Ensino Fundamental Valores 


\begin{abstract}
Souza Costa, F.A.B. de - Fundamental Teaching Teachers-Representation about themselves: a study about the Virtue of Love. São Paulo, 2007, 136 p. PHD thesis. Instituto de Psicologia. Universidade de São Paulo.
\end{abstract}

To discuss about the teachers' links with the Magistery and explain how these links carry on and last is one of the tasks that the Moral Psychology should incorporate in its investigation, considering the urgency of thinking about the moral dimension in the teachers' subjectivity and believing the human virtues are arrangements that many aspects: affective, cognitive, social, cultural, historical and others. Besides, in the Brazilian contemporary social teaching scenery, we consider how is important to know what the teachers think, which links they establish with their profession, their wishes, their motivations, their principles and worths. These inquietudes lead us to investigate which representations the teachers have about themselves in the fundamental teaching. The representations are images the people think about themselves and that they are formed as a whole of worths. For this, we made an investigation with sixty teachers of the Fundamental Teaching from the fifth to the eighth groups in different Brazilian cities with ages between twenty-one and sixty years old. We also asked if and how the virtue of love was in these representations about oneself. The investigation looked for identifying the people the teachers admire and their admirable marks. The results that our investigation gave us showed this: the people consider themselves as enthusiastic teachers, having positive attitudes considering the Education, teaching the student and his apprenticeships and they seemed curious and interested about knowledge. The informations we received also showed us the following questions: the human structure of the pupils, their development and apprenticeship appeared as an educative aim; the love, the passion, the gladness are primordial for teaching. Moral values as: respect, responsibility, solidarity, companionship were equally marked by the teachers and they consider very important to be encouraged among the pupils. Finally, we think that our hypothesis that the teachers who have the Virtue of Love as an important dimension in their representations about themselves is correct. They feel satisfied and realized personal and professionally.

Key-words: Virtues-Love-Representations of oneself- Teachers-Fundamental Teaching-Worths 